\title{
How does anisotropy in bedrock river granitic outcrops influence pothole genesis and development?
}

\author{
J.A. Ortega-Becerril ${ }^{1^{*}}$, M. Gómez-Heras ${ }^{2}$, R. Fort ${ }^{2}$, and E. Wohl ${ }^{3}$ \\ 1. Departamento de Geología y Geoquímica, Universidad Autónoma de \\ Madrid, Madrid. 28049, Spain. \\ 2. Instituto de Geociencias (CSIC,UCM), CEI-Moncloa, UCM-UPM, CSIC, \\ Madrid, Spain.Madrid 28040 Madrid, Spain. \\ 3. Department of Geosciences, Colorado State University, Fort Collins, CO \\ 80523-1482, USA. \\ * corresponding author: j.ortega@uam.es, phone 0034-914973833, fax 0034- \\ 914972982.
}

\begin{abstract}
:
Pothole formation and development may be influenced by joint sets and other heterogeneities within bedrock, as well as by hydraulics. Previous research indicates that most potholes found in rivers of the mountainous Spanish Central System exhibit preferred orientations associated with dominant joints and correlate more strongly with variations in substrate resistance than with hydraulics. Weathering and erosion weaken rock surfaces, which leads to decreased mechanical resistance. We start from the hypothesis that different mechanisms of pothole formation may create around the pothole a distinctive signature in terms of ultrasound pulse velocity and surface hardness. We develop a conceptual model and test it using potholes for which we know the
\end{abstract} been through the copyediting, typesetting, pagination and proofreading process which may lead to differences between this version and the Version of Record. Please cite this article as doi: 10.1002/esp.4054 
mechanism of formation, demonstrating that the spatial and statistical distributions of dynamical mechanical properties and surface hardness of a pothole may provide insight into its genesis.

KEYWORDS: potholes; anisotropy; weathering; ultrasound; Schmidt hammer.

\section{Introduction}

Stream potholes are erosive features developed in river channels. Potholes are present in diverse types of cohesive substrate, from soft material like clays to resistant bedrock such as granites. In many cases the genesis (origin and development) of these bedrock bedforms can be attributed to hydraulic forces that create localized abrasion, rather than any intrinsic properties of the bedrock (Richardson and Carling, 2005; Wilson et al., 2013; Wilson and Lave, 2013), jointing can play an important role in pothole initiation and development (Ortega et al., 2014). Processes that have been invoked for pothole genesis include glacial abrasion (Gilbert, 1906), mechanical abrasion by means of grinders (Charpentier, 1841), depressions eroded by subglacial melt water (Ljunger, 1930), and cavitation within eddies (Alexander, 1932; Nemec et al., 1982; Kale and Shingade, 1987; Springer et al., 2005, 2006; Sengupta and Kale, 2011; Lima and Binda, 2015). 
Pothole genesis, however, might be influenced by diverse substrate properties such as compressive or tensile rock strength (Selby, 1980; Hancock et al., 1998; Richardson and Carling, 2005; Springer et al., 2006; Wohl, 2008), as well as by heterogeneities (joints, veins, dikes, xenoliths) that were subsequently affected by weathering or abrasion by boulder impacts (Lorenc et al., 1994; Wang et al., 2009; Wilson et al., 2013; Ortega et al., 2014). Joints are a particularly important form of heterogeneity in pothole initiation and development (Elston, 1917; Ängeby, 1951; Springer et al., 2005; Ortega et al., 2014). Joints can also facilitate block quarrying (Whipple et al., 2000; Dubinski and Wohl, 2013) which can limit the duration of time available for pothole development on a particular surface.

There are complex feedbacks among hydraulics, substrate, and channel morphology, which reflect a balance between hydraulic driving forces and substrate erodibility of bedrock streams (Goode and Wohl, 2010). Spatial position of bedrock forms in river bed outcrops is dependent on the position and geometric configuration of the channel (Kale and Shingade, 1987) and on downstream obstructions that influence the pothole (Whipple et al. 2000; Wilson et al., 2013). Bed topography influences the flow structure and local turbulent intensity, and facilitates non-uniform abrasion due to non-uniform distribution of sediment impacts (Johnson and Whipple, 2007). Substrate heterogeneities lead to reach-scale concentration of hydraulic energy, as reflected in the positive correlation between rock erodibility and reach gradient (Goode and Wohl, 2010).

Pothole shapes vary from well rounded, symmetrical and deep, to irregular shapes with angular planform and shallow depths where multiple joints intersect the pothole. Between these end-members are a wide range of features that some authors explain as resulting from different durations of pothole formation (e.g., 
Lorenc et al., 1994) or processes involved (e.g., Ortega et al., 2014). We hypothesize that well rounded and symmetrical potholes (which we refer to as hydraulic potholes) are more likely to result from primarily hydraulic processes acting on a relatively homogeneous substrate and at locations characterized by strong flow separation, such as a knickpoint lip, lateral channel walls, or downstream from a boulder obstacle. In contrast, irregularly shaped potholes (which we refer to as structural potholes) occur at diverse locations within bedrock channels that have substrate heterogeneities. Most potholes within active channels reflect erosion that is influenced by hydraulics: the distinctions and terms above are used to differentiate the most important influences on individual potholes.

To achieve better knowledge of pothole genesis, many questions should be addressed, including: Are all river bed outcrop surfaces equally inherently susceptible to pothole erosion? Is weathering the primary cause of pothole initiation? Is substrate anisotropy the primary cause of pothole initiation? For the last two questions, it is necessary to understand the combined effects of substrate strength (for example, by using Schmidt hammer readings, $\mathrm{H}_{\mathrm{R}}$, as a surrogate of Uniaxial Compressive Strength), substrate weakness (joints), and substrate primary anisotropy within the context of the distribution of hydraulic forces at a site. In any case, it is essential to characterize substrate weakness and its anisotropy to answer these questions.

Plutonic rocks may present diverse scales of heterogeneity. Plutonic rocks tend to be isotropic at outcrop scale; i.e., their minerals do not tend to have preferred orientation. Nevertheless, a certain amount of mineral orientation can occur during granite emplacement due to magmatic flow. Also, after emplacement, during the erosional unroofing, granite may develop microcracks parallel to denuded surfaces in 
addition to larger scale sheeting joints due to off-loading or distribution of large-scale compressive strength. These types of relatively inconspicuous heterogeneities may affect a substantial mass of rock and are independent from joints, veins, or other localized heterogeneities. Anisotropy related to the pervasive network of microcracks is called primary anisotropy, whereas anisotropy resulting from joints and veins is called secondary anisotropy. Primary anisotropy conditions weathering and erosion processes, as the network of microcracks parallel to the surface favors scaling and flaking.

Strength characterization techniques based on sampling (such as standard Uniaxial Compressive Strength tests) are problematic in that sampling is necessarily restricted to specific points and may not be representative. This is also a problem in relation to protected areas such as national parks where sampling needs to be restricted (as in some of the areas studied for this research). Because of this, nondestructive techniques that allow multiple readings and therefore make it possible to map bedrock surfaces around potholes are an efficient way of characterizing surface mechanical properties for numerous potholes within a specified area (Ortega et al., 2014).

Surface hardness (Schmidt Hammer rebound test $-\mathrm{H}_{\mathrm{R}}$ ) and Ultrasound Pulse Velocity (UPV) are two techniques initially developed as non-destructive tests for concrete evaluation, but now used in geomorphic research (Goudie, 2006; Viles et al., 2011). $H_{R}$ and UPV values depend on the elastic properties of the rock. $H_{R}$ and UPV values are related to the petrophysical properties of the rock (Kahraman, 2001; Vasconcelos et al., 2007; Prikryl et al., 2007; Sharma et al., 2011; Cerna and Engel, 2011; Fort et al., 2010, 2011, 2013), but can be influenced by weathering and erosion. In general, lower UPV and $\mathrm{H}_{\mathrm{R}}$ values indicate less resistant rocks, which 
may reflect a higher degree of weathering. UPV and $\mathrm{H}_{\mathrm{R}}$ values are not only influenced by weathering but also by intrinsic material characteristics. Therefore, it is necessary to carry out population analyses to determine baseline values for unweathered rocks and, consequently, thresholds for each particular lithology and location in which rocks undergo weathering. Ortega et al. (2014) showed the benefits of a combined use of both techniques because of their different resolution. The Schmidt hammer rebound test is more sensitive to surface processes, such as scaling and flaking. UPV better penetrates the rock and is more efficient in detecting zones of weakness such as joints perpendicular to the surface (Selby, 1980). $H_{R}$ and UPV also have the advantage of being non-destructive analytical techniques, which allows minimizing sampling in natural protected areas.

In a previous paper, the relationship between the occurrence of potholes and joints was examined using Schmidt hammer and ultrasound velocity as tools to determine the heterogeneities in the substrate and to interpret the evolution and development of potholes after their initiation (Ortega et al., 2014). From the insights gained in this previous work, the next steps here are to (i) characterize the statistical distribution of UPV and $\mathrm{H}_{\mathrm{R}}$ values around potholes as a surrogate of rock strength and presence/absence of discontinuities, and (ii) establish whether these influence the formation of certain types of potholes and, conversely, whether different mechanisms of pothole formation may leave a distinctive signature in terms of UPV and $\mathrm{H}_{\mathrm{R}}$ value distribution around a pothole. This allows us to evaluate how planar discontinuities of bedrock influence pothole initiation and development, and what factors are primarily responsible for the bedrock anisotropy (rock type, jointing, fabric, others). Therefore, we investigate relationships between UPV and $H_{R}$ values and: (1) presence/absence of potholes in a bedrock outcrop, and (2) type of pothole 
developed. We use these investigations to generate insights into pothole initiation and genesis.

Previous work indicates that potholes can develop if hydraulic forces exceed thresholds for substrate erosion (Zen and Prestegaard, 1994; Whipple et al., 2000; Springer et al., 2005 and 2006; Wang et al., 2009). We hypothesize that hydraulic forces will be the primary control on potholes formed in erosionally resistant rocks with higher UPV values, as indicated by a weak correlation between pothole locations or dimensions and measures of rock strength. In contrast, substrate heterogeneities will be the primary control on potholes formed in weaker rocks with lower UPV values, as indicated by stronger correlations between pothole formation and measures of rock strength.

We envision four combinations of UPV and $\mathrm{H}_{R}$ values (Fig. 1). We assume that high/low UPV groups indicate lower/higher abundance of discontinuities and high/low $\mathrm{H}_{\mathrm{R}}$ groups indicate higher/lower rock resistance.

\section{Study area}

The Spanish Central System is a broad mountain range that crosses most of the Iberian Peninsula from SW to NE (Fig. 2). The range developed during the Variscan orogeny and contains diverse crystalline rocks of Palaeozoic age, although granites predominate. We examined bedrock outcrops at three study sites on different tributaries of the Tagus River: the Tietar, Alberche, and Manzanares. Porphyric biotitic monzogranite outcrops at Tietar (TM, site 1), porphyric leucogranite outcrops at Alberche (AB, site 2), and coarse-grained leucogranite with interbedded microdiorite dikes outcrops at Manzanares (MCV, site 3). Table 1 summarizes relevant hydrological and morphological characteristics of the study sites. 
Floods result from frontal systems in winter and snowmelt during late spring, but intense convective storms are common during autumn. The flood-peak discharge with a 500-year recurrence $Q_{500}$ exceeds $Q_{2}$, the annual peak discharge by six to eight times at the study sites (Table 1). The Tietar and Alberche sites are rapids and the Manzanares site is a knickpoint. Tietar and Alberche transport pebble-cobble gravel bedload. The Manzanares site has more exposed bedrock, although boulders are present up- and downstream from the knickpoint.

Crystal size and mineral composition are the main petrographic characteristics that influence potential differences in weathering and erosion between the study sites: coarser crystals and plagioclase and mafic minerals weather more readily, as recognized since work by Goldich (1938). Figure 3 shows thin sections of fresh rock extracted from areas where potholes were not present. Of the three sites, Manzanares (Figure 3a) has the coarsest crystals, as well as having more homogeneous crystal size distribution and the lowest content of mafic minerals. Alberche and especially Tietar (Figs $3 b$ and $3 c$ ) are finer-grained and nonequigranular. Tietar has a slightly higher content of mafic minerals than Alberche.

\section{Methods}

UPV and $\mathrm{H}_{\mathrm{R}}$ analyses were carried out in an area approximately 50-100 m long and 30-40 m wide at each of the three sites. Each of these sites was chosen because of the presence of numerous potholes and joints. The bedrock was drilled vertically and cores were extracted. At each site, cores were extracted from areas without potholes outside the active channel and from areas where potholes were present. A maximum of three cores were extracted in each site, as the test areas are placed in protected areas (national and regional parks) where sampling needs to be 
kept to the minimum. The "caps" of the cores (approximately $1 \mathrm{~cm}$ ) were removed to avoid the more weathered surface and UPV was measured for each core in the $\mathrm{X}, \mathrm{Y}$, and $Z$ directions to determine the anisotropy of the rock. These cores were also used to petrographically examine areas with and without potholes.

A Proceq N-type Schmidt hammer applying an impact energy of $2.207 \mathrm{~N} \cdot \mathrm{m}$, was used to measure the rebound number $\mathrm{H}_{\mathrm{R}}$ as a magnitude related to Uniaxial Compressive Strength. Measurements were taken with the plunger tip pointing down and perpendicularly to the surface.

CNS Electronics PUNDIT portable test equipment was used for measuring the time-of-flight of ultrasonic p-waves in $\mu \mathrm{s}$ (accuracy $\pm 0.1 \mu \mathrm{s}$ ). For field measurements, the system included $54 \mathrm{kHz}$ transducers with a round, $50 \mathrm{~mm}$-diameter contact surface. Transducers were fixed into a wooden frame so that the distance between the centers of the transducers was kept constant at $15 \mathrm{~cm}$ in order to make velocity calculations straightforward. A fine layer of plasticine-like clay was used to improve the sonic continuity between the rock and the transducers. Measurements were taken using the indirect mode of transmission (i.e., both sensors are placed parallel on the same surface, as described by Alvarez de Buergo and Gonzalez, 1994). This method is commonly used in building materials testing when only one surface of the assessed element is accessible and sensors cannot be opposed, analogous to the rock surfaces where the potholes are found. Although pulse velocity determined by the indirect method may be slightly different to that using the direct method, this difference can be neglected when making ultrasound pulse velocity maps, as velocity is only assessed relative to the overall distribution. As UPV measurements included areas with different weathering degrees, data dispersion was very high. We prefer to include raw results in the tables, although they might exceed the number of 
significant figures given the high standard deviation, as these raw results were used for statistical population analyses.

For extracted cores, UPV was measured on cores using the "direct method" (Alvarez de Buergo and Gonzalez, 1994); i.e., the transmitting and receiving transducers are placed on opposite surfaces of the cores. $1 \mathrm{MHz}$ transducers were used with ultrasound gel as a coupling agent. The differences between transducers array (direct vs indirect method), coupling agent (gel vs plasticine) and transducers pulse frequency ( $1 \mathrm{MHz}$ vs $54 \mathrm{kHz}$ ) lead to variations in the UPV measured on cores and the velocity measured on outcrops. The UPV measured on cores is closer to the real UPV of the rock mass, due to a more efficient transmission of ultrasound pulses. Anisotropy in relation to ultrasound was calculated on the cores by means of anisotropy indices $d m$ and $d M$. These indices are calculated using standard formulae that relate the higher, lower, and intermediate UPV measures for each measured sample:

$$
\begin{aligned}
& d M \%=\left[1-\left(2 V_{\text {lower }} /\left(V_{\text {intermediate }}+V_{\text {higher }}\right)\right] \times 100\right. \\
& d m \%=\left[\left(2 x\left(V_{\text {higher }}-V_{\text {intermediate }}\right) /\left(V_{\text {higher }}-V_{\text {intermediate }}\right] \times 100\right.\right.
\end{aligned}
$$

A higher index value indicates greater anisotropy. It is important to note that $d M$ includes the velocities measured for all three axes, whereas $d m$ excludes the lowest velocity. Hence, $d M$ expresses the overall anisotropy of the rock, whereas $d m$ reflects anisotropy along weakness planes. For example, a slate will have very high $d M$ as a result of schistosity, but may have or may not have a high $d m$ because, once the lowest velocity is removed (which corresponds to the direction perpendicular to the schistosity), $d m$ will measure the anisotropy within the 
anisotropy plane (Guydader and Denis, 1986). Therefore, isotropic rocks will have low and similar values of $d M$ and $d m$, whereas rocks with clear parallel weakness planes will have high $d M$ and may or may not have high $d m$ values (Fort et al., 2011).

We started with the assumption that potholes that were equidimensional or symmetrical in shape and close to the active channel resulted primarily from hydraulic forces, whereas potholes that were asymmetric and farther from the channel reflected a strong influence of heterogeneities in the bedrock. Systematic field measurements involved the selection of 18 potholes, including some expected to have a structural genesis and some expected to have a hydraulic genesis based on appearance (well rounded, near active channel, polished surfaces).

Measurements in each pothole were taken following a grid with $15 \mathrm{~cm}$ mesh, measuring $\mathrm{H}_{\mathrm{R}}$ and UPV values at each intersection point in the grid. Each grid included at least 64 measurements $(8 \times 8)$. The spatial extent of the grids varied in each case, but was sufficient to cover the pothole and $40-60 \mathrm{~cm}$ around the pothole. The strength of bedrock was determined using a standard N-type Schmidt hammer, as described above. The sample size suggested by Selby (1980) was doubled and at least 50 rebound values per site were measured, as Niedzielski et al. (2009) suggested strong rocks $(R>50)$ such as granite may require a larger sample.

A population analysis was carried out to establish groups within the total set of measurements of UPV and $\mathrm{H}_{\mathrm{R}}$ in each river bed. For the three sites, overall, we made 1259 UPV measurements in and around potholes and 266 in bedrock without potholes. We made $1279 \mathrm{H}_{\mathrm{R}}$ measurements in and around potholes and 266 in bedrock without potholes. The number of UPV measurements is lower than the number of HR measurements because the size of the transducers array made it 
impossible to take some measurements at points where HR was measured. The population analysis followed the methodology of Vázquez-Calvo et al. (2010), plotting the values in a normal probability plot. This allows grouping the measurements in different populations characterized by a normal distribution. By separating different populations, we can differentiate baseline values for unweathered rock (population with higher UPV) from different degrees of weathered rock (populations with lower UPV) (Vázquez Calvo et al., 2010). Other factors, such as fractured areas, will also stand out as different populations.

\section{Results}

\subsection{Rock weathering}

A factor to be considered in interpreting the initiation and evolution of potholes and therefore the interpretation of UPV and $H_{R}$ variations is the influence of rock weathering in relation to erosion. Feldspars and biotite group minerals exhibit the highest weathering susceptibility. Clay inclusions within feldspars resulting from hydrolysis are easily observable with a microscope and characterize the granites in the three study areas. Petrographic analyses aimed to characterize if weathering patterns were different for each of the studied granites and whether there were significant differences between the degree of weathering in areas with and without potholes. Petrographic analyses of core samples show an overall higher degree of weathering in Tietar samples (TM). This is not surprising, given that biotite group minerals are more abundant in Tietar granite than in Manzanares (MCV) and Alberche (AB) leucogranites. Comparing areas with and without potholes, there is a substantially higher degree of weathering in the areas with potholes, as observed by the higher degree of mineral alteration, mainly in biotite group minerals and 
feldspars. This is especially noticeable in the Manzanares and Alberche samples (Figure 4). Both plagioclase and K-feldspar are prone to chemical weathering (hydrolysis). Weathering of feldspar takes place preferentially at the boundary of twinned and untwinned domains (Eggleton and Buseck, 1980). Feldspar hydrolysis releases aqueous silica, so it is common to see silica cements associated with feldspar alteration.

\subsection{Anisotropy analysis in cores}

Mean values of UPV for each core extracted in the three study areas are shown in Table 2. Because $X$ was oriented along $N-S$, these initial $X, Y$, and $Z$ values can be converted into N-S, E-W and vertical.

Tietar granites have significantly higher mean UPV values $\left(4685-4287 \mathrm{~ms}^{-1}\right)$ than those in Alberche (3863-3464 ms $\left.{ }^{-1}\right)$ and Manzanares $\left(3503-3303 \mathrm{~ms}^{-1}\right)$, which do not show statistically significant differences (student's t-test; $\alpha=0.05$ ). In Alberche and Tietar granites (both microporphyric), the Z-axis UPV is significantly lower than values for the $\mathrm{X}$ and $\mathrm{Y}$ axes. This corresponds to marked discontinuities parallel to the horizontal surface, as shown by the high $d M$ anisotropy index, a trend that is more marked in Alberche. Manzanares granites display the lowest anisotropy index, so they do not show marked preferred orientation of the crystalline fabric in fresh rock. Differences between areas with and without potholes are not significant. 


\section{3. $\quad H_{R}$ and UPV values in non-potholed outcrops}

The non-potholed areas measured in each of the three sites show differences. UPV values range from 4052 to $6522 \mathrm{~ms}^{-1}$ at the Tietar site, from 2632 to $6522 \mathrm{~ms}^{-1}$ at the Manzanares site, and from 1948 to $3750 \mathrm{~ms}^{-1}$ at the Alberche site. Average $\mathrm{H}_{R}$ values are $54 \pm 6(64-32 \mathrm{max} / \mathrm{min})$ at the Tietar site, $55 \pm 4(62-42 \mathrm{max} / \mathrm{min})$ at the Manzanares site and $46 \pm 9(60-30 \mathrm{max} / \mathrm{min})$ at the Alberche site.

Results from non-potholed outcrops indicate that "fresh rock" has higher UPV values at Tietar and Manzanares but lower values at Alberche (Fig. 5). High UPV values may reflect the fact that there are not planar discontinuities between the transducers and therefore the rock is not heavily fractured or weathered. Therefore, non-potholed outcrops at Tietar and Manzanares are clearly different than those at Alberche. There are no joints or they are barely found at Manzanares, whereas Tietar and Alberche have similar joint density and orientation.

As shown in Table 3, the percentage of values for each of three main populations was calculated. The highest values in relation to UPV were interpreted as corresponding to unweathered or minimally weathered granites without many joints (population I). The intermediate population was interpreted as granites moderately jointed (population II), whereas the lowest UPV values would indicate weathered and/or densely jointed granites (population III). Two populations, A and B, were established for $\mathrm{H}_{\mathrm{R}}$ values), corresponding to a qualitative classification of hard granite $(A)$ and soft granite $(B)$. 
Populations I and A (unweathered and hard granite) are clearly represented in Manzanares and Tietar. Data distribution in Alberche is very different from the other two areas, with I and II populations of UPV and A and B of $\mathrm{H}_{\mathrm{R}}$. This is interpreted as a coexistence of soft and more weathered rock with relatively unweathered hard rock.

\section{4. $\quad H_{R}$ and UPV values in potholed outcrops and statistical analysis}

A summary of the mean, standard deviation, and number of measurements of $H_{R}$ and UPV for 6 representative potholes reported in Ortega et al. (2013), as well as the population analyses, are shown in Table 4. Values vary among the three sites, but in general most of the lower values come from Alberche, whereas higher values come from Tietar.

For the UPV measurements in the potholed outcrops, granite at the Tietar site has the highest values $\left(4286 \pm 1374 \mathrm{~ms}^{-1}\right)$, followed by Manzanares $(4067 \pm 1502$ $\left.\mathrm{ms}^{-1}\right)$ and Alberche $\left(3215 \pm 1105 \mathrm{~ms}^{-1}\right)$. Standard deviation in all areas is very high, being larger than $1000 \mathrm{~ms}^{-1}$ in many cases (Table 4). This indicates a large dispersion of data, mainly because of the difference between UPV values close to the pothole and those from more distant areas, as described by Ortega et al (2013). The highest average $H_{R}$ values come from Tietar (55 \pm 9$)$, closely followed by Manzanares (54 \pm 9$)$ and with differences to Alberche (46 \pm 12$)$.

As mentioned above, the population distribution of UPV and $\mathrm{H}_{\mathrm{R}}$ values is different for each site (Figure 6), dependent on the degree of weathering and presence of joints. Although these three populations can be found at all the study sites (Table 3), the thresholds between populations differ in relation to the specific petrological characteristics of each granite. At Tietar and Manzanares, the threshold 
between populations I and II is approximately $3700 \mathrm{~ms}^{-1}$, whereas at Alberche it is $2700 \mathrm{~ms}^{-1}$.

Two populations can be defined for $\mathrm{H}_{\mathrm{R}}$ values, with a threshold at around 48 . Population A has higher values and corresponds to hard and sound granite, whereas lower values correspond to weathered areas in granites with soft surfaces.

Plotting the values of $\mathrm{H}_{R}$ and UPV for each of the points measured at every site (Figure 7), it is again clear that there are two different groups of ultrasound UPV values. This could be interpreted as the difference between unweathered and weathered bedrock (around $3700 \mathrm{~m} . \mathrm{s}^{-1}$ UPV in Tietar and Manzanares and unclear at the Alberche site), or as the result of some local weaknesses, which in turn could condition the development of the potholes. The $\mathrm{H}_{\mathrm{R}}$ results do not reflect clear groups of potholes, at least at Alberche. A slight separation at $\mathrm{H}_{R}=48$ might exist at the other two sites.

A detailed analysis of all potholes suggests that results are for the most part clearly divided into high and low UPV values (Fig. 8A). Examining the distribution of data points in Fig. 8 suggests which potholes are more resistant (e.g., pothole TM-39 in Fig. 8) or less resistant, with two populations at lower values (e.g., pothole MCV40 in Fig. 8).

\section{Discussion}

Direct UPV measurements of the extracted cores referred to in Table 2 (i.e., those measurements taken by opposing transducers and therefore taking into account the bulk rock), show there are no significant differences in UPV in areas with and without potholes, nor a significant increase in anisotropy. 
Tietar granite is more compact and therefore average UPV values are higher than in Alberche and Manzanares in areas with and without potholes. Alberche granite shows a noticeably higher overall anisotropy (dM\%) than Manzanares and Tietar. This indicates well developed planar structures parallel to the surface, which in turn may lead to flaking, scaling and spalling. In addition, non-potholed outcrops are located farther from the channel at the Alberche site than at Tietar and Manzanares. Because of this, outcrops at Alberche are less frequently flooded than those at Tietar and Manzanares and therefore undergo less fluvial abrasion. Fluvial abrasion removes granite flakes and scales generated by weathering processes and helps to expose new bedrock surfaces. Therefore, this continuous bedrock removal is reflected in higher values of $H_{R}$ and UPV. For that reason, less frequently flooded, non-potholed outcrops, such as those from Alberche, show lower values of $\mathrm{H}_{R}$ and UPV than those at Tietar and Manzanares.

These results also suggest the importance of the role of rock anisotropy and the existence of a pervasive network of microcracks parallel to the surface, and subsequent scaling, in pothole evolution. For a pothole to develop, vertical erosion should equal or exceed lateral erosion (for example, Pelletier et al., 2015, suggest a maximum shear stress at the bottom of the pothole to create a pothole geometry with depth/radius $=1$, and maximum typical values of depth/radius $=3$ ). In anisotropic rocks with a dense network of microcracks parallel to the surface, spalling and subsequent bedrock removal by fluvial abrasion would be more frequent. Therefore, lateral erosion would exceed incision and pothole development could be inhibited. 
UPV and $\mathrm{H}_{\mathrm{R}}$ results show a polymodal clustering around certain values. This suggests a much more complex interpretation than in the conceptual scheme in Figure 1, where four situations were proposed in relation to the presence/absence of discontinuities and the bulk resistance of the bedrock.

Individual pothole analysis indicates the existence of several populations in relation to UPV and $\mathrm{H}_{\mathrm{R}}$. As mentioned earlier, these different populations reflect, for UPV, the coexistence around the pothole of areas with more or less planar discontinuities (dikes, joints, cracks) and, for $\mathrm{H}_{\mathrm{R}}$, more intensely weathered and unweathered areas.

Therefore, it could be hypothesized that the type of data clustering may be an indication of the processes involved in the formation of potholes in an area. Figures 6, 7 and 8 show the different thresholds between clustered data associated with the studied areas. These limits are found at approximately 1500, 2700 and 3700 m.s ${ }^{-1}$ (depending on the studied area) for UPV and 45-48 Schmidt number for $\mathrm{H}_{\mathrm{R}}$. The conceptual scheme proposed in Figure 1 might therefore be modified as shown in Figure 9 to better reflect these areas of data clustering.

Figure 9a exemplifies the rationale explained earlier, in which a certain pattern of data clustering reflects a specific process of pothole formation. For a pothole formed purely by hydraulic processes (i.e., not in an area with planar discontinuities nor in a heavily weathered area), measured data would cluster in the field of higher UPV and $\mathrm{H}_{\mathrm{R}}$. If a single planar discontinuity (e.g., a joint) seeded the formation of a pothole, the data would show two clusters, as in Figure 9b; a higher UPV and $\mathrm{H}_{R}$ cluster corresponding to the areas around the pothole without discontinuities and another cluster of lower UPV values corresponding to the area around the discontinuities. Moreover, if the whole area around the pothole contains abundant 
planar discontinuities and the pothole develops from one of these, data would cluster in two populations, as shown in Figure 9c.

Something similar occurs in relation to $\mathrm{H}_{R}$ values, depending on how actively the area around the pothole is eroded. If the subaerially weathered surfaces around a pothole are frequently removed by, for example, spalling of weathered debris due to more regular stream flow, $\mathrm{H}_{\mathrm{R}}$ data will be relatively high because the measurements are always made on "fresh" rock (this is the case in Figures $9 \mathrm{a}, \mathrm{b}$ and c). However, if the erosion rate on and around the pothole is very slow relative to weathering rate, $\mathrm{H}_{\mathrm{R}}$ data would spread, showing a distribution similar to those in Figures $9 d$, e and $f$.

To better understand how these data cluster and how, for example, values of UPV around potholes at the Alberche study site differ from those at Tietar and Manzanares, it is necessary to compare multiple, relevant variables: the geomorphic environment, rock heterogeneity, hydraulics, and rock substrate properties. With respect to geomorphic environment and channel morphology, the Alberche and Tietar sites are rapids with well-developed channel morphology. The Manzanares site is a knickpoint that is likely changing rapidly and has less mature erosional features. Jointing seems to be similar between the three sites. As we demonstrated previously (Ortega et al., 2014), joint locations correlate well with the main pothole axes and probably exert an important role in pothole development. Hydraulics differ between Manzanares and the other sites, with lower mean discharge but constrained flow that is very effective in lateral bank erosion at Manzanares.

Therefore, considering the substrate erodibility and anisotropy, along with hydraulics, allows us to explain differences in data clustering between the three sites. Individual pothole analysis indicates two types of data clustering. First, the 
potholes at Tietar and Manzanares show two clusters divided by an ultrasound value of $3700 \mathrm{~m} \cdot \mathrm{s}^{-1}$. The second type is exemplified by potholes at the Alberche site, where most data cluster together.

Figure 10 shows the interpretation of how these data clusters relate to the different processes and features associated with pothole formation in the studied sites. Weathered areas without erosion of the weathered surface have values of approximately $<1500 \mathrm{~m} . \mathrm{s}^{-1}$; areas with joints that may trigger pothole initiation along the bedrock have values of $2000-3000$ m.s ${ }^{-1}$; and massive fresh rock, where hydraulic potholes could be dominant, has values $>4000 \mathrm{~m} . \mathrm{s}^{-1}$. Ortega et al. (2014) suggested the possibility of hidden joints not externally visible that nonetheless influence pothole development. Potholes may also form with no relation to joints. Potholes not apparently associated with joints tend be well rounded, rather than elongated in planform, and seem to result from flow separation along the boundaries of the active channel.

$\mathrm{H}_{\mathrm{R}}$ and UPV results show two very different trends: one in Manzanares and Tietar and another in Alberche. It is important to remember the extremely high anisotropy shown in cores extracted from the area without potholes, with a high degree of planar discontinuities parallel to the surface. Sound, unweathered rock is expected to show the highest values of $\mathrm{H}_{\mathrm{R}}$ and UPV (as is the case at the Tietar and Manzanares sites). A homogeneous, sound, unweathered body of rock will show values clustered around one point (Fig. 11a). A body of rock with planar discontinuities, such as joints, will show a bimodal distribution in relation to UPV (Fig 11b), with the highest values corresponding to the areas between discontinuities and the lowest values to those measurements affected by the discontinuity. If weathering and erosion lower the strength of rock in a non-homogeneous manner, $\mathrm{H}_{\mathrm{R}}$ values will 
show a bimodal distribution (Fig. 11c), with the lowest values corresponding to weathered areas. If this heterogeneous weathering takes place around planar discontinuities, the statistical distribution of values will appear as in Fig. 11d.

We propose that if pothole formation reflects primarily hydraulics, an initial situation shown in Figure 11a would evolve to that shown in 11c, whereas if potholes are controlled primarily by substrate discontinuities, pothole evolution would go from $11 \mathrm{~b}$ to $11 \mathrm{~d}$ as erosion and weathering take place. Based on this inference, statistical analyses of the distribution of data around potholes and comparison to the distribution of data in an area without potholes could provide insight into pothole formation as well as the processes involved in pothole evolution and/or degree of maturity. Measurements in areas without potholes in Manzanares and Tietar correspond to case (a), whereas the area without potholes at Alberche corresponds to an area with deep weathering and planar discontinuities (parallel to the surface in this case), closer to (d).-At the other sites, potholes interpreted to be primarily hydraulic in genesis have similar values to those interpreted to result primarily from weathering. Considering $\mathrm{H}_{\mathrm{R}}$ values, potholes such as TM-39 have higher values than the average at the site (62 vs 55-58).

Local heterogeneities identified on the basis of UPV and $\mathrm{H}_{\mathrm{R}}$ measurements act either as a weak points (easily erodible points that lead to development of potholes) or hard points (potholes developed due to differential erosion created by flow separation) in which potholes initiate by means of the combined effect of chemical and mechanical weathering.

$H_{R}$ indicates rock strength, and according to Lima and Binda (2015), may not be a primary variable of pothole formation. Erosion does not necessarily lower rock strength (for example, a surface that is polished by continuous flow erosion may not 
show weakening) and, also, the initial stages of chemical weathering may not lower rock strength. In this sense, $\mathrm{H}_{\mathrm{R}}$ may not necessarily be a good indicator for the formation of a pothole, as noted by Lima and Binda (2015). However, the results in this paper show $\mathrm{H}_{\mathrm{R}}$ may be a relevant indicator of the predominance of weathering processes over flow erosion in an area or, on the contrary, when flow erosion is still an active process in bedrock outcrops. Hence, $\mathrm{H}_{\mathrm{R}}$ plays an important role in analyzing pothole genesis.

Therefore, because UPV is more sensitive to discontinuities and heterogeneities even for unweathered/non-eroded rock, it is a better indicator than $\mathrm{H}_{\mathrm{R}}$ to characterize these heterogeneities in the bedrock that are crucial, first for pothole initiation and later for pothole development. UPV is also a good indicator of the evolution point of a reach in a bedrock river in terms of active erosion or stabilization of active processes in different stages of geomorphological features. UPV values can reflect changes from an active flow-erosional reach with a knickpoint (Manzanares) to a moderately active flow-erosional reach with rapids (Tietar) and, finally, to an open bedrock channel with weathering as a dominant process (Alberche), where potholes can be present as a result of past conditions (climatic, discharge, stream power). This can be supported by the existence of "dirty potholes", covered by moss or slope debris and not recently eroded, with clear spalling and a rough surface. The distinctive signature in terms of UPV and $\mathrm{H}_{R}$ value distribution around a pothole may be then used as a detection tool of geomorphological and hydrological stability in a bedrock reach. 


\section{New insights into processes prevalent in pothole evolution}

We now reformulate our conceptual model from four fields to six fields (Fig. 9). The origin of the initial depression that can become a pothole is related to rock properties and anisotropy. More anisotropic outcrops tend to develop depressions. Once the pothole is created, its development is a function of the joint geometry and substrate heterogeneities that allow flow to elongate depressions along dominant joint sets via flow separation. The evolution of potholes is highly dependent on the proximity of the pothole to the active channel, which governs the relative importance of weathering versus fluvial erosion. Frequent flows erode the surfaces of potholes spalling from small-scale joints.

Understanding pothole genesis requires using methods that reflect subsurface rock properties, as these properties might influence the mechanism and processes of pothole formation. The insights developed from these data can be used to separate potholes according to their origin or age, facilitating insights beyond those of the classical studies that used other visual or qualitative methods for classifying potholes (i.e., Lorenc et al., 1994; Richardson and Carling, 2005). The new approach described here can provide tools for understanding how bedrock incision rates are influenced by rock type, rock properties (anisotropy), substrate heterogeneities (jointing, dikes), climatic conditions that affect weathering (spalling, disaggregation), and hydraulic factors or surrogate variables such as drainage area or stream power (local energy, vorticity, flow pattern). 


\section{Conclusions}

The research summarized here employs a non-destructive analytical approach and demonstrates how, through the combined use of UPV and HR, the dominant processes in pothole genesis and subsequent development may be interpreted. These dominant processes can be related to: lithological structural factors, such as rock discontinuities ranging from unroofing microcracks to joints and dikes; hydraulic forces; and relative rates of weathering versus erosion.

In terms of the methodological approach, UPV has been shown as a good method to test rock anisotropy and degree of weathering in bedrock outcrops, as well as the existence of substrate discontinuities that may not be visually apparent.

The location of potholes in a bedrock river reach may reflect changes in bedrock anisotropy and/or presence of discontinuities. Higher UPV values indicate compact bedrock, which normally relates to high pothole density. UPV anisotropy may indicate the existence of well-developed planar structures parallel to the surface, which in turn may lead to flaking, scaling, and spalling. In this scenario, potholes cannot grow deeper because of the predominance of weathering processes over incisive flow erosion.

The patterns of pothole formation observed with respect to distance from the active channel and flood regime reinforce the inference that frequently eroded bedrock close to the channel has a smooth surface on which hydraulic processes are dominant in controlling pothole genesis. At greater distances from the channel, the bedrock surface in and around potholes becomes rougher and more irregular and weathering processes dominate pothole genesis. 
The new approach described here can provide tools for understanding how bedrock incision rates are influenced by rock properties (anisotropy), substrate heterogeneities (jointing, dikes), weathering rates (spalling, disaggregation), and hydraulic factors or surrogate variables such as drainage area or stream power (local energy, vorticity, flow pattern).

\section{Acknowledgements}

This research was partially funded by Geomateriales 2 programme (S2013/MIT2914) funded by the Regional Government of Madrid (Spain). JAO's participation in this study was supported by the Jose Castillejo Grant (CAS14/00073, Ministry of Education, Culture and Sports, Spain).

\section{References}

Alexander HS. 1932. Pothole erosion. Journal of Geology 40(4): 305-337

Alvarez de Buergo M, González T. 1994. Estudio del método de la medida de la velocidad de propagación del sonido y su aplicación a edificios históricos. Ingeniería Civil 94: 69-74.

Ängeby O. 1951. Pothole erosion in recent water-falls. Lund Studies in Geography 2: $1-34$.

Cerna B, Engel Z. 2011. Surface and sub-surface Schmidt hammer rebound value variation for a granite outcrop. Earth Surface Processes and Landforms 36(2): 170-179. DOI: 10.1002/esp.2029.

Charpentier JF. 1841. Essai sur les glaciers: Et sur le terrain erratique du bassin du Rhône. Lausanne, M. Ducloux. 
De Puy GW. 1965. Petrographic investigations of rock durability and comparisons of various test procedures. Bulletin American Association Engineering Geologists 2: 31-46.

Dubinski IM, Wohl E. 2013. Relationships between block quarrying, bed shear stress, and stream power: a physical model of block quarrying of a jointed bedrock channel. Geomorphology 180-181: 66-81. DOI:10.1016/j.geomorph.2012.09.007.

Eggleton RA, Buseck PR. 1980. High resolution electron microscopy of feldspar weathering. Clays and Clay Minerals 28: 173-178.

Elston ED. 1917. Potholes: their variety, origin and significance (I). Scientific Montly 5: 554-567.

Fort R, Alvarez de Buergo M, Perez-Monserrat E, Varas MJ. 2010. Characterisation of monzogranitic batholiths as a supply source for heritage construction in the northwest of Madrid. Engineering Geology 115: 149-157. DOI: 10.1016/j.enggeo.2009.09.001.

Fort R, Varas MJ, Alvarez de Buergo M, Martin-Freire D. 2011. Determination of anisotropy to enhance the durability of natural stone. Journal of Geophysics and Engineering 8: S132-S144. DOI: 10.1088/1742-2132/8/3/S13.

Fort R, Alvarez de Buergo M, Perez-Monserrat EM. 2013. Non-destructive testing for the assessment of granite decay in heritage structures compared to quarry stone. International Journal of Rock Mechanics and Mining Sciences, 61; 296-305. DOI: 10.1016/j.jjrmms.2012.12.048.

Gilbert GK. 1906. Moulin work under glaciers. Geological Society of America Bulletin 17: 317-320. 
Goldich SS. 1938. A Study in Rock Weathering. Journal of Geology 46: 17-58. DOI:10.1086/624619.

Goode JR, Wohl EE. 2010. Substrate controls on the longitudinal profile of bedrock channels: implications for reach-scale roughness. Journal of Geophysical Research 115: F03018. DOI:10.1029/2008JF001188.

Goudie AS. 2006. The Schmidt Hammer in geomorphologial research. Progress in Physical Geography 30 (6): 703-718 DOI: 10.1177/0309133306071954.

Guydader J, Denis A. 1986. Propagation des ondes dans les roches anisotropies sous contrainte évaluation de la qualité des schistes ardoisiers. Bulletin of Engineering Geology 33: 49-55.

Hancock GS, Anderson RS, Whipple KX. 1998. Beyond power: Bedrock river incision process and form. In: K.J. Tinkler and E. Wohl (Eds). Rivers Over Rock: Fluvial Processes in Bedrock Channels, AGU monograph, 107, 35-60.

Johnson JP, Whipple KX. 2007. Feedbacks between erosion and sediment transport in experimental bedrock channels. Earth Surface Processes and Landforms 32(7): 1048-1062. DOI: 10.1002/esp.1471.

Kahraman S. 2001. A correlation between P-wave velocity, number of joints and Schmidt hammer rebound number. International Journal of Rock Mechanics and Mining Sciences 38: 729-33. DOI:10.1016/S1365-1609(01)00034-X.

Kale VS, Shingade BS. 1987. A morphological study of potholes of Indrayani knick point (Maharashtra). Explorations in the Tropics 206-214.

Lima AG, Binda AL. 2015. Differential control in the formation of river potholes on basalts of the Paraná Volcanic Province, Journal of South American Earth Sciences, 59: 86-94. doi:10.1016/j.jsames.2015.02.004. 
Lorenc MW, Barco PM, Saavedra J. 1994. The evolution of potholes in granite bedrock, W Spain. Catena 22(4): 265-274. DOI:10.1016/03418162(94)90037-X.

Ljunger E. 1930. Spaltentektonik und morphologie der schwedichen SkagerakKüste. Bulletin of Geological Institute of Upsala 21: 1-255.

Nemec W, Lorenc MW, Saavedra J. 1982. Potholed granite terrace in the Rio Salor valley, western Spain: A study of bedrock erosion by floods. Tecniterrae 50: 621.

Niedzielski T, Migon P, Placek A. 2009. A minimum sample size required from Schmidt hammer measurements. Earth Surface Processes and Landforms 34: 1713-1725. DOI:10.1002/esp.1851.

Ortega JA, Gómez-Heras M, Perez-López R, Wohl E. 2014. Multiscale structural and lithologic controls in the development of stream potholes on granite bedrock rivers. Geomorphology 204: 588-598. DOI:10.1016/j.geomorph.2013.09.005.

Pelletier JD, Sweeney KE, Roering JJ, Finnegan NJ, 2015. Controls on the geometry of potholes in bedrock channels. Geophysical Research Letters 42(3): 797803.

Prikryl R, Lokajícekb T, Prosa Z, Klímab K. 2007. Fabric symmetry of low anisotropic rocks inferred from ultrasonic sounding: Implications for the geomechanical models. Tectonophysics 431(1-4): 83-96. DOI:10.1016/j.tecto.2006.05.031.

Richardson K, Carling PA. 2005. A Typology of Sculpted Forms in Open Bedrock Channels. Geological Society of America Special Paper 392. DOI:10.1130/08137-2392-2.1. 
Selby MJ. 1980. A rock mass strength classification for geomorphic purposes: With tests from Antarctica and New Zealand. Zeitschrift Fur Geomorphologie 24(1): $31-51$.

Sharma PK, Khandelwal M, Singh TN. 2011. A correlation between Schmidt hammer rebound numbers with impact strength index, slake durability index and Pwave velocity. International Journal of Earth Sciences 100, 189-95. DOI: 10.1007/s00531-009-0506-5.

Springer GS, Tooth S, Wohl EE. 2005. Dynamics of pothole growth as defined by field data and geometrical description. Journal of Geophysical Research 110: F04010. DOI: 0.1029/2005JF000321.

Springer GS, Tooth S, Wohl EE. 2006. Theoretical modeling of stream potholes based upon empirical observations from the Orange River, Republic of South Africa. Geomorphology 82: 160-176. DOI:10.1016/j.geomorph.2005.09.023.

Vasconcelos G, Lourenço PB, Alves CSA, Pamplona J. 2007. Prediction of the mechanical properties of granites by ultrasonic pulse velocity and schmidt hammer hardness. In: North American Masonry Conference: 980-991.

Vázquez-Calvo C, Varas MJ, Alvarez de Buergo M, Fort R. 2010. Limestone on the Don Pedro I facade in the Real Alcázar compound, Seville, Spain. Geological Society London Sp. Publication - Limestone in the Built Environment: PresentDay Challenges for the Preservation of the Past. Smith, B.J., Gómez-Heras, M., Viles, H.A., Cassar, J. (Editors).331, 171-182. DOI: 10.1144/SP331.15 0305-8719/10.

Viles H, Goudie A, Grab S, Lalley J. 2011. The use of the Schmidt Hammer and Equotip for rock hardness assessment in geomorphology and heritage 
science: a comparative analysis. Earth Surface Processes and Landforms 36: 320-33. DOI:10.1002/esp.2040.

Wang W, Liang M, Huang S. 2009. Formation and development of stream potholes in a gorge in Guangdong. Journal of Geographical Sciences, 19(1): 118-128. DOI: $10.1007 / \mathrm{s} 11442-009-0118-9$.

Whipple KX, Hancock GS, Anderson RS. 2000. River incision into bedrock: Mechanics and relative efficacy of plucking, abrasion, and cavitation. Geological Society of American Bulletin 112(3): 490-503. DOI: 10.1130/00167606(2000)112<490:RIIBMA>2.0.CO;2.

Wilson A, Lavé J. 2013. The legacy of impact conditions in morphometrics of percussion marks on fluvial bedrock surfaces. Geomorphology 186: 174-180. DOI:10.1016/j.geomorph.2012.12.033.

Wilson A, Hovius N, Turowski JM. 2013. Upstream-facing convex surfaces: Bedrock bedforms produced by fluvial bedload abrasion. Geomorphology 180-181: 187-204. DOI: 10.1016/j.geomorph.2012.10.010.

Wohl EE. 2008. The effect of bedrock jointing on the formation of straths in the Cache la Poudre River drainage, Colorado Front Range. Journal of Geophysical Research: Earth Surface 113: F01007. DOI:10.1029/2007JF000817.

Zen E, Prestegaard KL. 1994. Possible hydraulic significance of two kinds of potholes: Examples from the paleo-Potomac River. Geology 22(1): 47-50. 
Table 1. Hydro-morphologic characteristics of the study sites. Q2 is flow with average recurrence interval of 2 years. Q500 is flow with average recurrence interval of 500 years. $S$ is reach-scale channel gradient

\begin{tabular}{lccccc}
\hline Site & $\begin{array}{c}\text { Drainage } \\
\text { area }\left(\mathrm{km}^{2}\right)\end{array}$ & $\mathrm{Q} 2\left(\mathrm{~m}^{3} \cdot \mathrm{s}^{-1}\right)$ & $\mathrm{Q} 500\left(\mathrm{~m}^{3} \cdot \mathrm{s}^{-1}\right)$ & $\mathrm{S}(\mathrm{m} / \mathrm{m})$ & Channel width $(\mathrm{m})$ \\
\hline Manzanares & 50 & 24 & 145 & 0.12 & $10-15$ \\
Alberche & 480 & 157 & 1213 & 0.2 & $20-40$ \\
Tietar & 301 & 82 & 543 & 0.012 & $10-15$ \\
\hline
\end{tabular}

Table 2. Summary of results of UPV measured in the three main axes with the direct method (opposed transducers) on the extracted cores, including $d M$ and $d m$ anisotropy indices. WP: with potholes, WoP: without potholes

\begin{tabular}{|c|c|c|c|c|c|c|c|c|c|c|c|}
\hline & & \multicolumn{6}{|c|}{ UPV $\left(m \cdot s^{-1}\right)$} & \multirow{2}{*}{\multicolumn{2}{|c|}{$\frac{\operatorname{UPV}\left(m \cdot \mathrm{s}^{-1}\right)}{\operatorname{MEAN}}$}} & \multicolumn{2}{|c|}{ Anisotropy } \\
\hline & & \multicolumn{2}{|c|}{$\begin{array}{c}\text { Direction X } \\
(\mathrm{N}-\mathrm{S})\end{array}$} & \multicolumn{2}{|c|}{$\begin{array}{c}\text { Direction } Y \\
(E-W)\end{array}$} & \multicolumn{2}{|c|}{ Vertical Z } & & & \multirow{2}{*}{$\mathrm{dM} \%$} & \multirow{2}{*}{$\mathrm{dm} \%$} \\
\hline & & Mean & std & Mean & std & Mean & std & Mean & std & & \\
\hline \multirow{3}{*}{ Manzanares } & M-WP1 & 3599 & 102 & 3264 & 132 & 3646 & 34 & 3503 & 198 & 9.89 & 1.3 \\
\hline & M-WP2 & 3371 & 48 & 3280 & 187 & 3257 & 58 & 3303 & 117 & 2.7 & 2.74 \\
\hline & M-WoP1 & 3327 & 70 & 3809 & 45 & 3328 & 83 & 3488 & 245 & 3.78 & 13.48 \\
\hline \multirow{3}{*}{ Alberche } & AB-WP1 & 4170 & 59 & 4056 & 153 & 3272 & 151 & 3833 & 433 & 20.45 & 2.77 \\
\hline & AB-WP3 & 3675 & 56 & 3846 & 51 & 2873 & 108 & 3464 & 448 & 23.61 & 4.55 \\
\hline & AB-WoP2 & 3974 & 169 & 4264 & 133 & 3351 & 107 & 3863 & 41 & 18.64 & 7.02 \\
\hline \multirow{3}{*}{ Tietar } & T-WP2 & 4996 & 73 & 4743 & 81 & 4317 & 46 & 4685 & 299 & 11.35 & 5.2 \\
\hline & T-WP1 & 4835 & 115 & 4569 & 89 & 4396 & 35 & 4600 & 204 & 6.5 & 5.65 \\
\hline & T-WoP1 & 4565 & 123 & 4356 & 170 & 3940 & 68 & 4287 & 295 & 11.66 & 4.67 \\
\hline
\end{tabular}


Table 3. Percentage of population in each pothole, as defined by UPV (I, II and III) and $H_{R}$ values $(A$ and $B)$.

\begin{tabular}{|c|c|c|c|c|c|c|c|}
\hline \multirow{2}{*}{$\begin{array}{c}\text { River } \\
\text { Manzanares }\end{array}$} & \multirow[t]{2}{*}{ No potholes } & \multicolumn{6}{|c|}{ Potholes } \\
\hline & & MCV-31 & MCV-37 & MCV-38 & MCV-40 & MCV-16 & MCV-64 \\
\hline \multicolumn{8}{|l|}{ UPV (\%) } \\
\hline I & 98 & 81 & 30 & 26 & 17 & 76 & 49 \\
\hline II & 2 & 10 & 42 & 53 & 44 & 18 & 39 \\
\hline III & 0 & 9 & 28 & 21 & 39 & 6 & 12 \\
\hline \multicolumn{8}{|l|}{$\mathrm{H}_{\mathrm{R}}(\%)$} \\
\hline A & 94 & 94 & 48 & 76 & 68 & 60 & 94 \\
\hline B & 2 & 6 & 40 & 21 & 27 & 37 & 5 \\
\hline Alberche & No potholes & AB38 & AB45 & AB48 & AB68 & AB42 & AB28 \\
\hline \multicolumn{8}{|l|}{ UPV (\%) } \\
\hline 1 & 52 & 92 & 68 & 96 & 95 & 29 & 32 \\
\hline II & 48 & 8 & 32 & 4 & 5 & 71 & 60 \\
\hline III & 0 & 0 & 0 & 0 & 0 & 0 & 8 \\
\hline \multicolumn{8}{|l|}{$H_{R}(\%)$} \\
\hline A & 36 & 42 & 59 & 22 & 14 & 52 & 36 \\
\hline B & 41 & 74 & 15 & 30 & 38 & 29 & 41 \\
\hline Tietar & No potholes & TM-6 & TM-25 & TM-37 & TM-39 & TM-24 & TM-38 \\
\hline \multicolumn{8}{|l|}{ UPV (\%) } \\
\hline I & 100 & 77 & 42 & 50 & 69 & 56 & 58 \\
\hline II & 0 & 21 & 54 & 45 & 31 & 40 & 36 \\
\hline III & 0 & 2 & 4 & 5 & 0 & 4 & 6 \\
\hline \multicolumn{8}{|l|}{$\mathrm{H}_{\mathrm{R}}(\%)$} \\
\hline$A$ & 86 & 96 & 92 & 77 & 100 & 63 & 93 \\
\hline B & 6 & 3 & 8 & 22 & 0 & 31 & 6 \\
\hline
\end{tabular}


Table 4. UPV and $H_{R}$ values for potholes at the three sites, with standard deviation and total number of points in every pothole

\begin{tabular}{|c|c|c|c|c|c|c|c|}
\hline & & \multicolumn{3}{|c|}{ UPV } & \multicolumn{3}{|c|}{$\mathrm{H}_{\mathrm{R}}$} \\
\hline & & Mean & $\begin{array}{l}\text { Std. } \\
\text { dev. }\end{array}$ & $\begin{array}{l}\text { Points } \\
\mathrm{N}\end{array}$ & Mean & $\begin{array}{l}\text { Std. } \\
\text { dev. }\end{array}$ & $\begin{array}{l}\text { Points } \\
\mathrm{N}\end{array}$ \\
\hline \multirow{7}{*}{ Manzanares } & MCV-31 & 4898 & 1252 & 68 & 60 & 6 & 67 \\
\hline & MCV-37 & 3065 & 1583 & 56 & 50 & 11 & 52 \\
\hline & MCV-38 & 3500 & 1461 & 34 & 55 & 11 & 34 \\
\hline & MCV-40 & 2823 & 1064 & 36 & 54 & 10 & 37 \\
\hline & MCV-16 & 4936 & 1161 & 51 & 49 & 10 & 52 \\
\hline & MCV-64 & 4232 & 1383 & 96 & 55 & 5 & 98 \\
\hline & All & 4067 & 1502 & 341 & 54 & 9 & 340 \\
\hline \multirow{7}{*}{ Alberche } & AB-38 & 4030 & 1242 & 115 & 43 & 14 & 118 \\
\hline & AB-45 & 3041 & 914 & 74 & 53 & 10 & 74 \\
\hline & AB-48 & 3749 & 1090 & 48 & 45 & 14 & 53 \\
\hline & AB-68 & 3762 & 1065 & 60 & 41 & 11 & 63 \\
\hline & AB-42 & 2439 & 431 & 93 & 50 & 6 & 92 \\
\hline & AB-28 & 2474 & 660 & 77 & 45 & 11 & 82 \\
\hline & All & 3215 & 1105 & 467 & 46 & 12 & 482 \\
\hline \multirow{7}{*}{ Tietar } & TM-6 & 4712 & 1253 & 107 & 58 & 5 & 103 \\
\hline & TM-25 & 3967 & 1325 & 50 & 56 & 7 & 50 \\
\hline & TM-37 & 3822 & 1276 & 104 & 55 & 12 & 106 \\
\hline & TM-39 & 4506 & 1080 & 32 & 62 & 3 & 40 \\
\hline & TM-24 & 4379 & 1463 & 87 & 48 & 11 & 87 \\
\hline & TM-38 & 4332 & 1531 & 71 & 56 & 5 & 71 \\
\hline & All & 4286 & 1374 & 451 & 55 & 9 & 457 \\
\hline
\end{tabular}



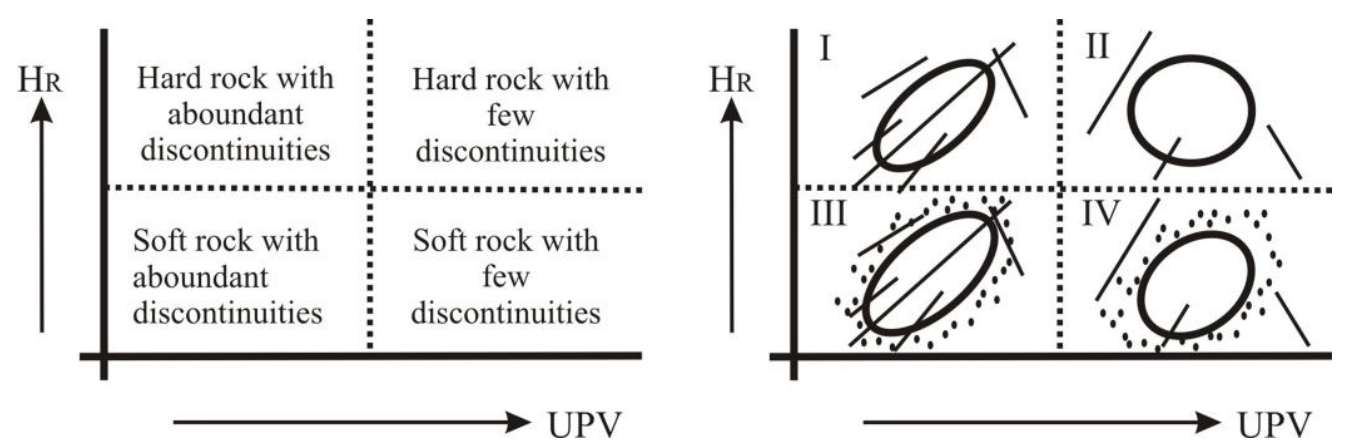

Fig.1. a. Conceptual scheme of four potential combinations of UPV and HR values. $b$.

Same four fields as in a, but representing graphically the combination of weathered areas (represented as dots) which would result in low HR values and joints and other linear discontinuities (straight lines) that would lower UPV. Ovals represent potholes.

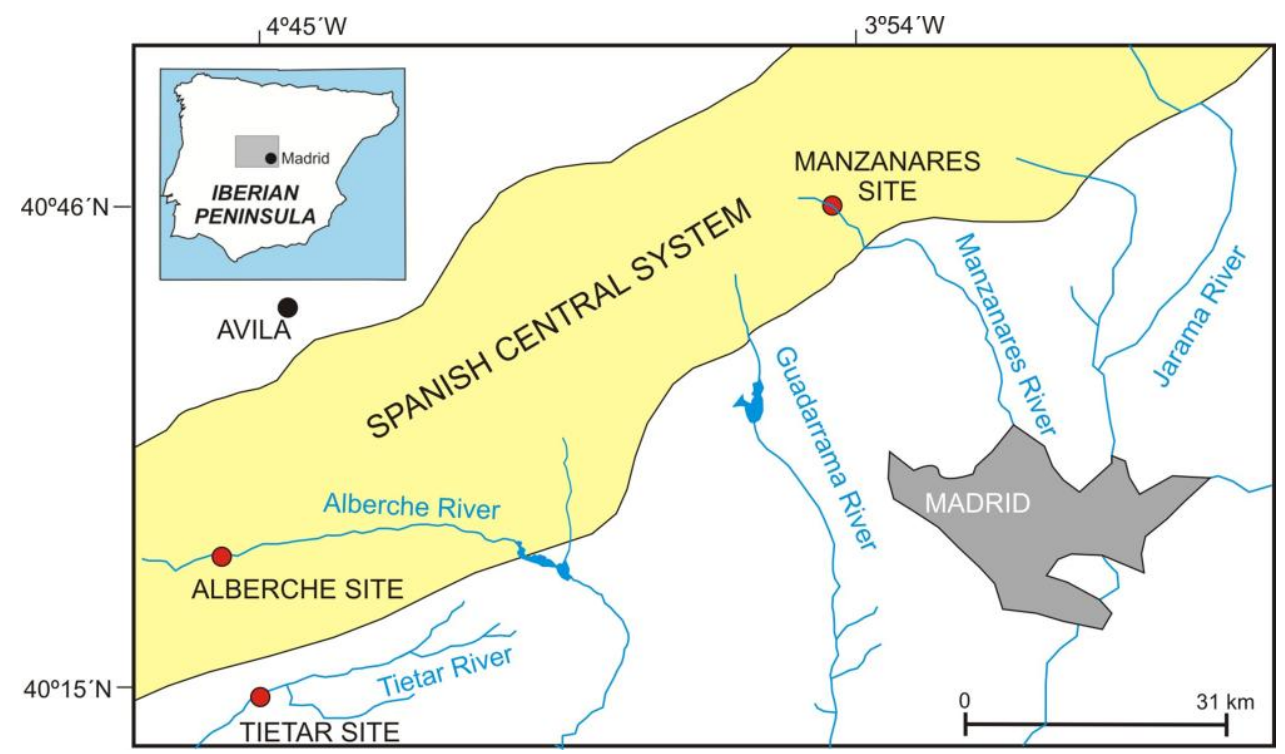

Fig. 2. Study area. Red dots indicate study sites 

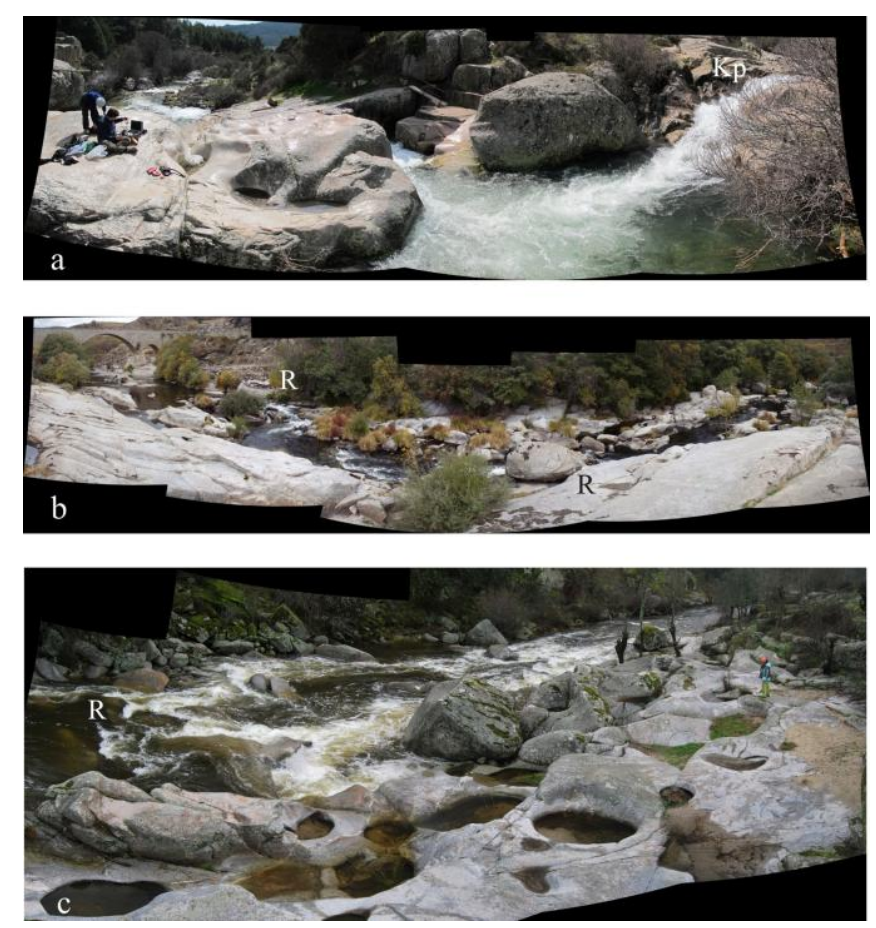

Fig. 3. Pictures of the three studied reaches: a. Site 1 in Manzanares River, b. Site 2 in Alberche River, c. Site 3 in Tietar River. 

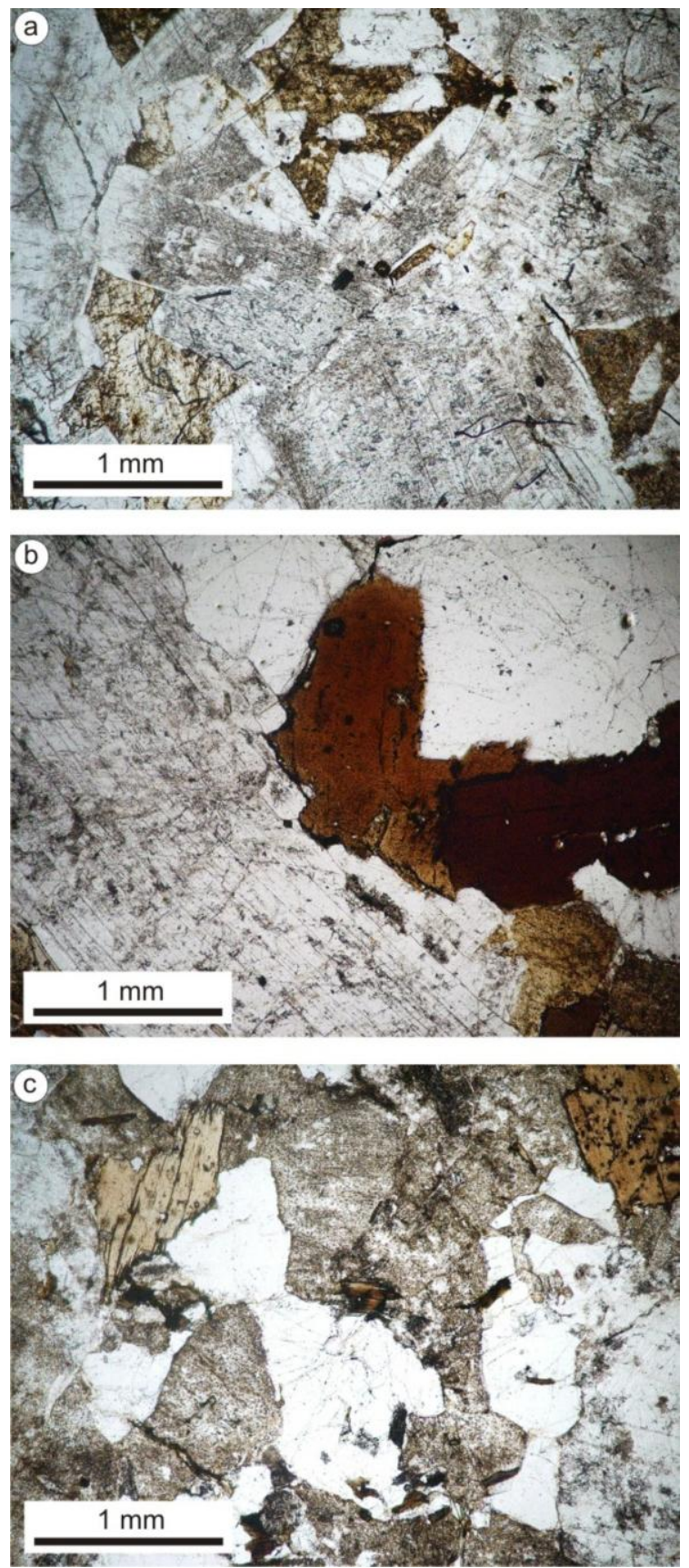

Fig 4: Polarizing microscope (parallel polars) thin section photomicrographs showing the different grain size and texture of fresh granite outcrops from the three studied sites: a) Manzanares b) Alberche c) Tietar 

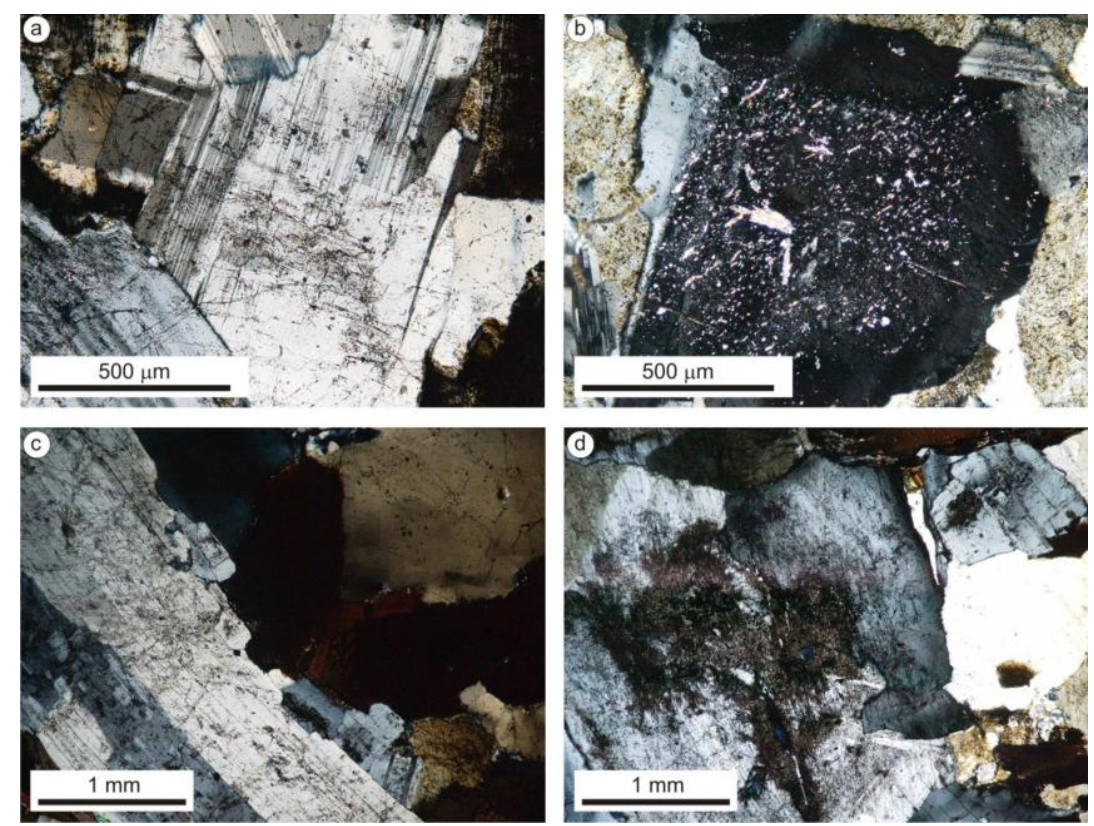

Figure 5. Photomicrographs of feldspar crystals showing the higher degree of alteration to clay minerals in the broad areas where potholes are developed. This process takes place in the three areas, but it is more noticeable in Manzanares and Alberche: a) Manzanares no potholes, b) Manzanares potholes, c) Alberche no potholes, d) Alberche potholes 


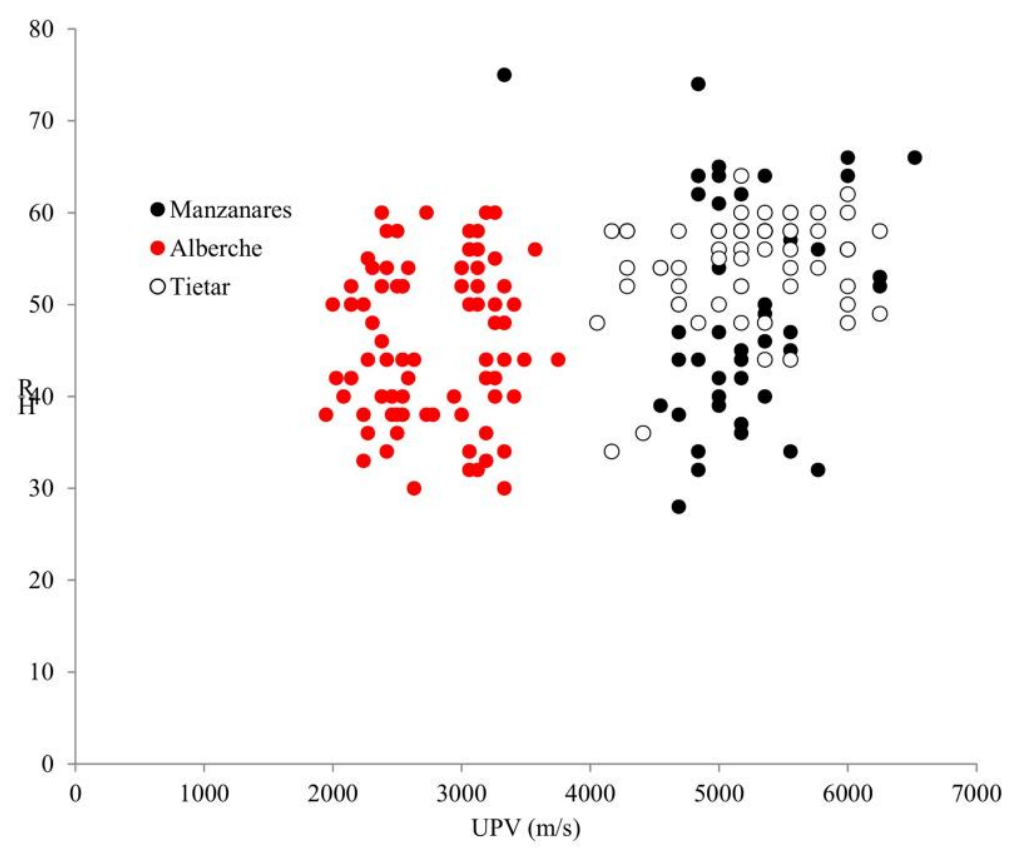

Fig. 6. Clustering of data from ultrasound analysis in non-potholed outcrops. 

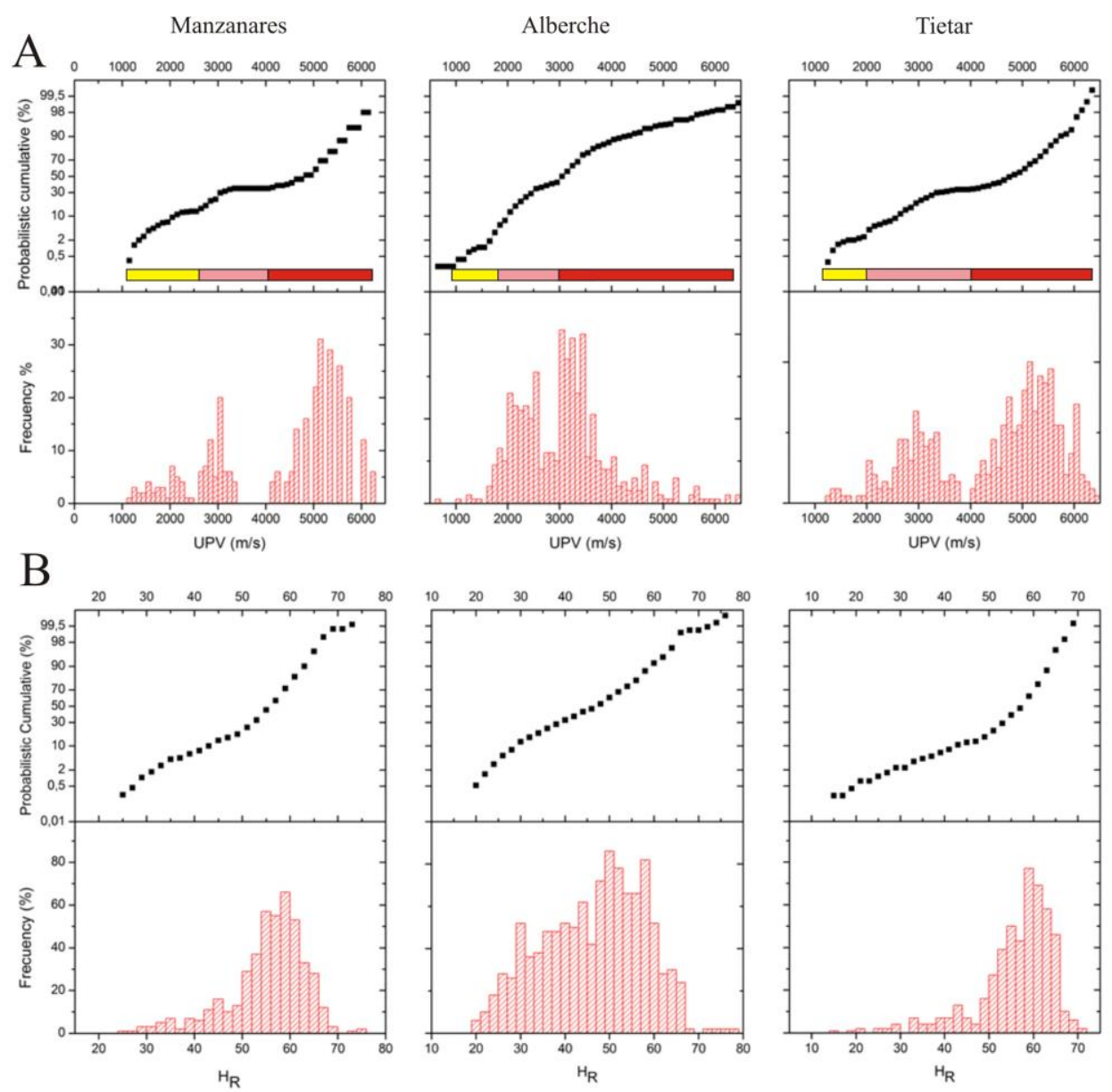

Fig 7. A. Results in ultrasound (UPV) statistical analysis for the three sites and B. Results in Schmidt hammer (HR) statistical analysis. 

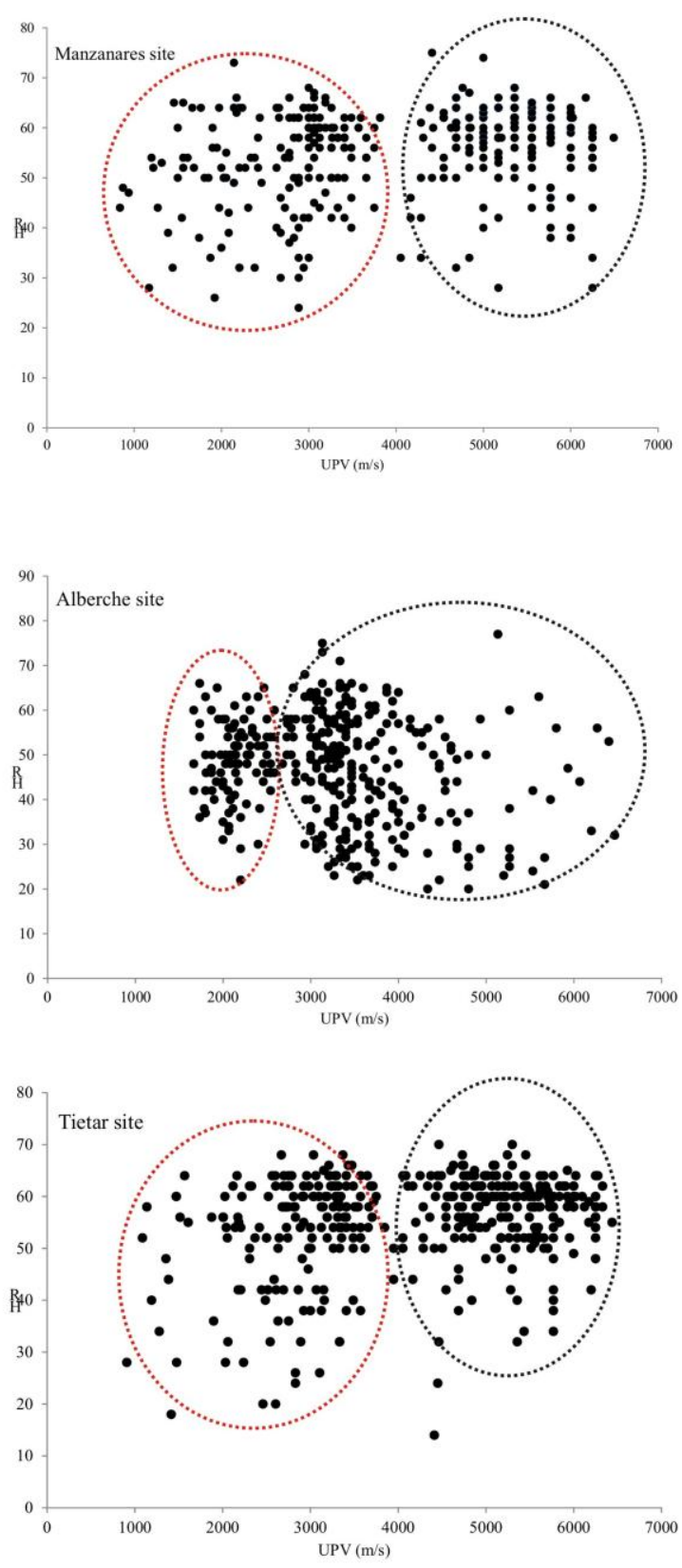

Fig. 8. HR vs UPV plots in all selected potholes and the three studied sites. Circles represent populations clearly separated by UPV values. 

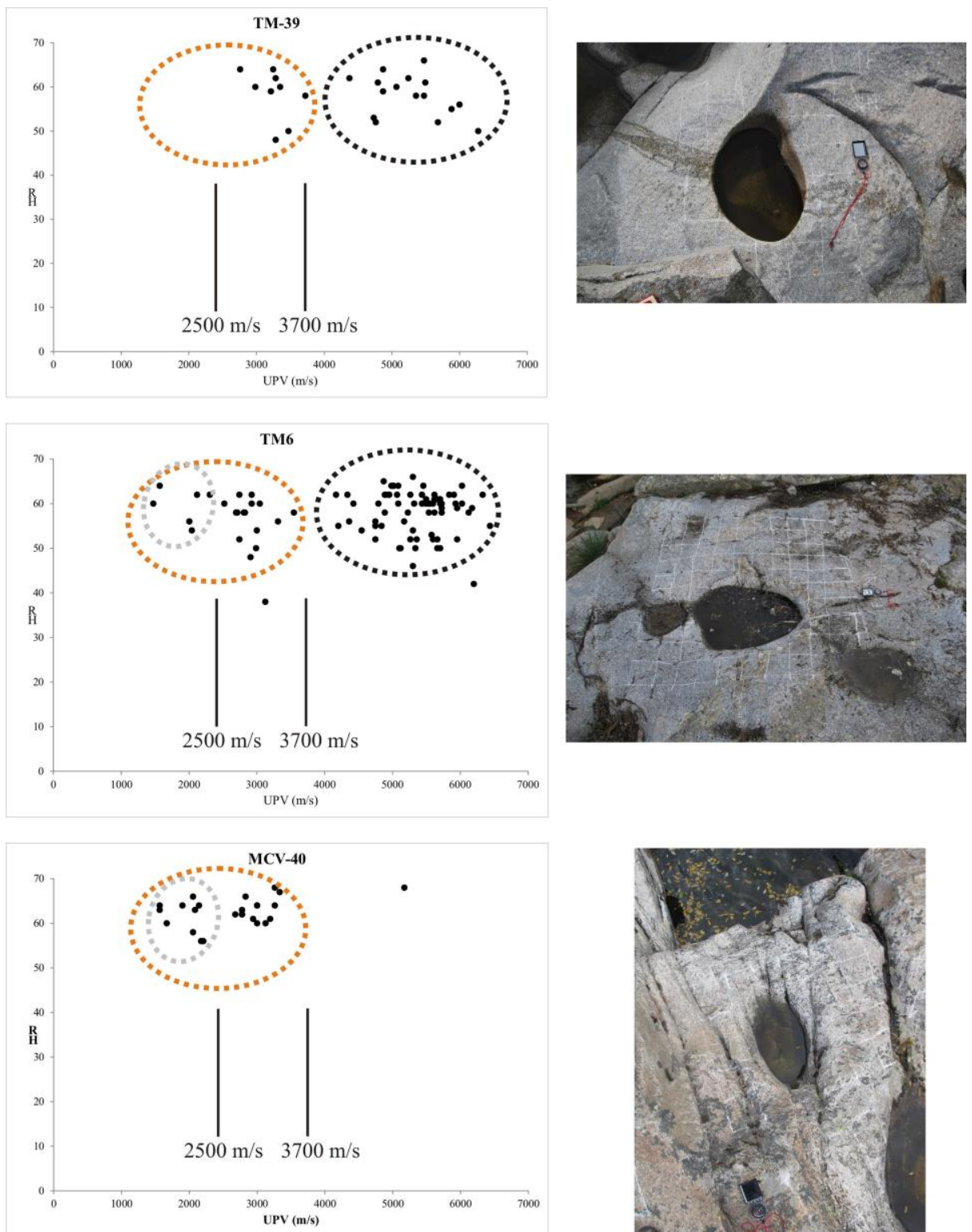

Fig. 9. Examples of clustering in UPV results. A. Primary clustering in two main groups higher (black) and lower (red) of $3700 \mathrm{~m} / \mathrm{s}$. B. Example of pothole with clustering in higher values of UPV. C. Example of pothole with clustering in lower UPV values. Grey circle shows another group lower than $2500 \mathrm{~m} / \mathrm{s}$ that can be identified in some potholes. 


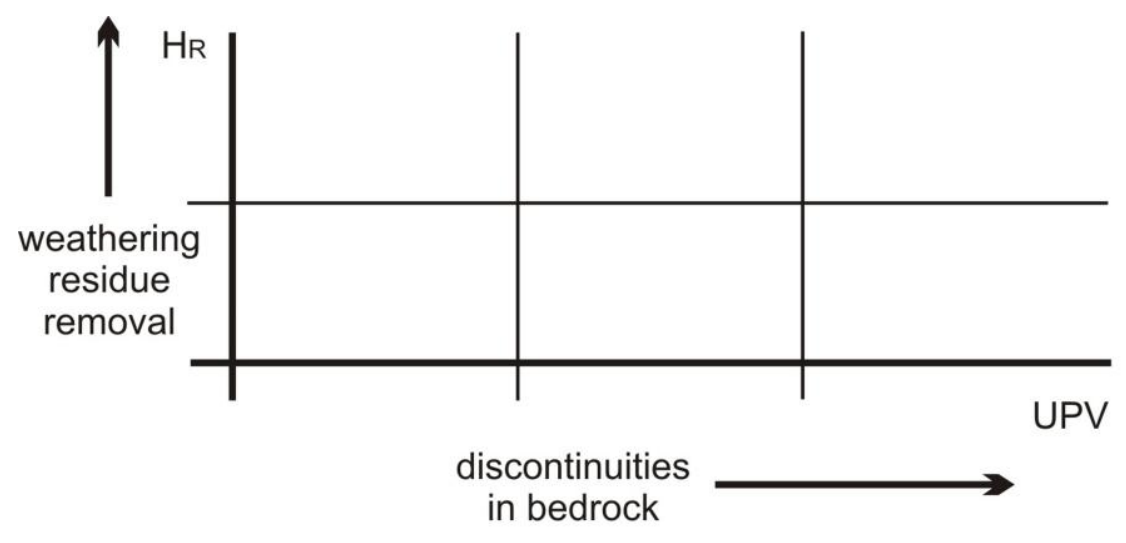

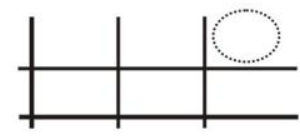

a)
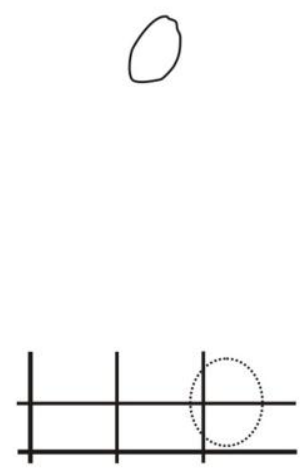

d)

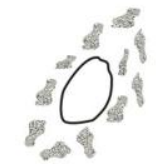

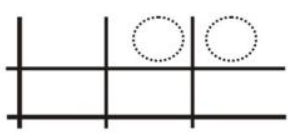

b)
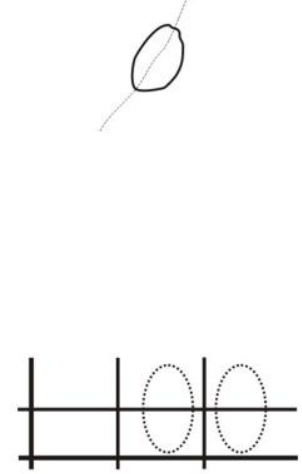

e)

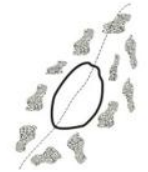

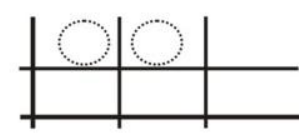

c)
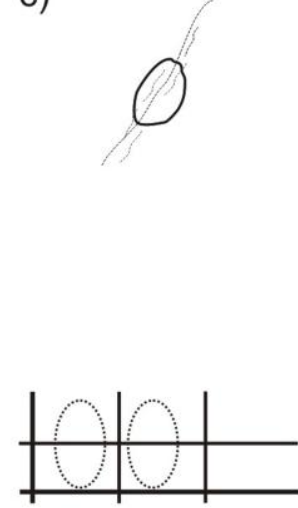

f)

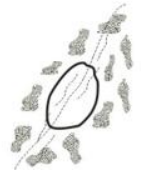

Fig 10. Change in previous conceptual model resulting from new insights. Details in text. 


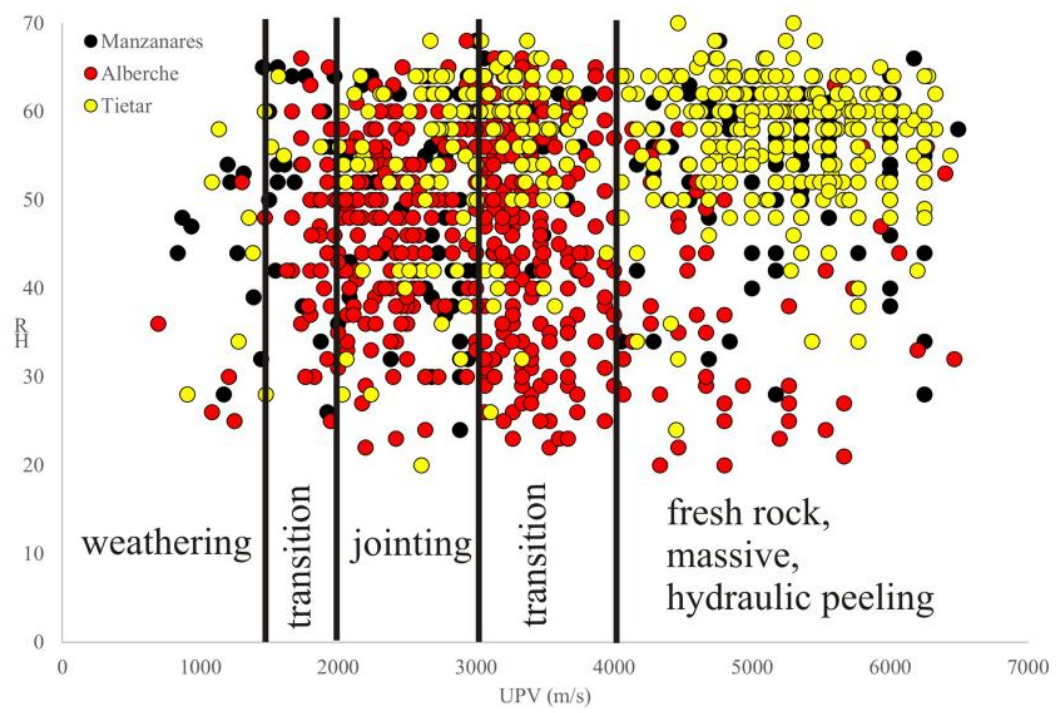

Fig. 11. Fields of dominant processes in potholes derived from UPV analysis 


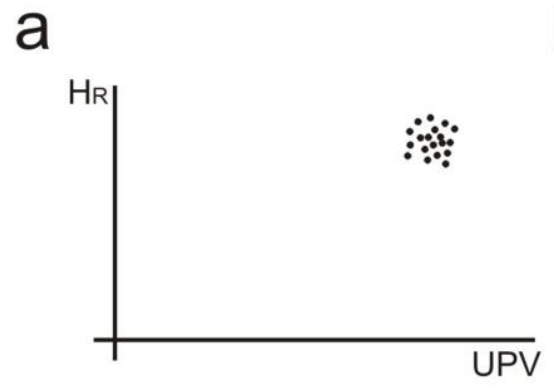

b
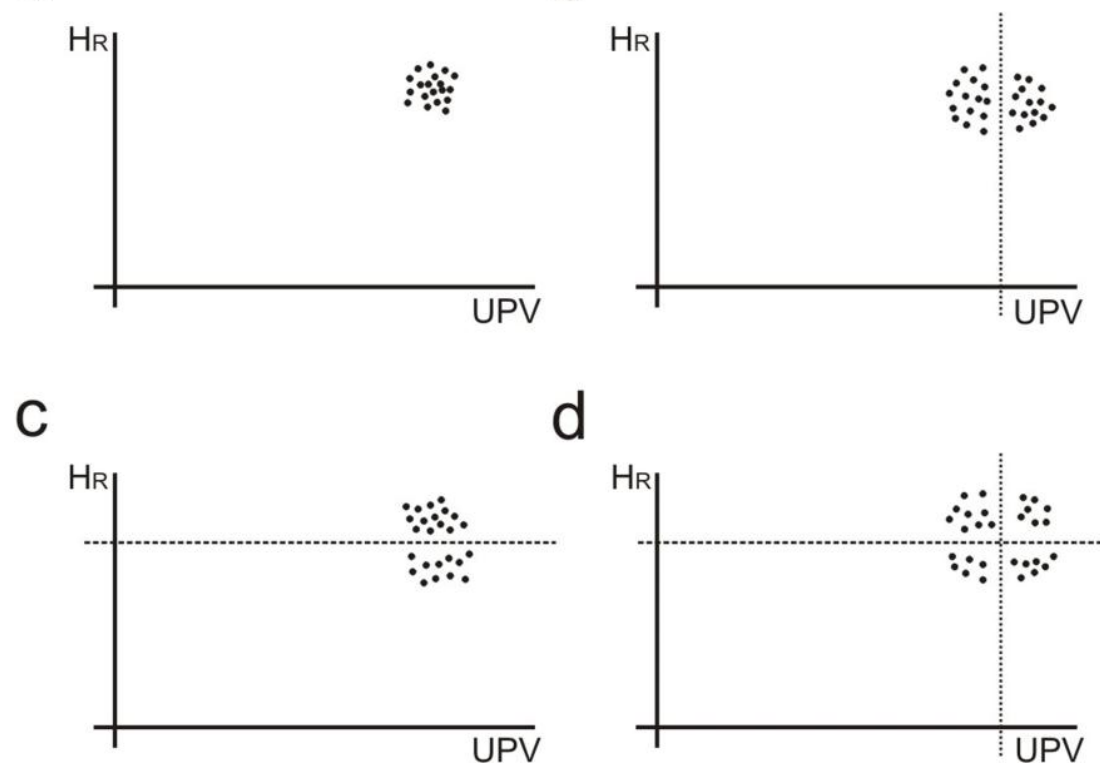

d

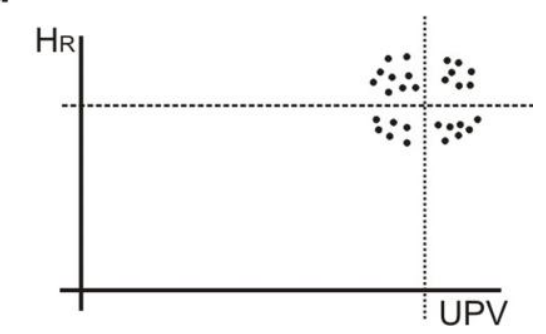

Fig. 12. Different clusters of statistical data depending on HR and UPV. See text for explanation of clustering patterns 